\title{
Journal of Pharmaceutical Analytics and Insights
}

\section{Quality by Design Approach for Establishment of Stability Indicating Method for Determination of Cefditoren Pivoxil}

\author{
Mohamed Gad', Hala E Zaazaa ${ }^{2 *}$, Sawsan M Amer ${ }^{2}$ and Mohamed A Korany ${ }^{3}$ \\ ${ }^{1}$ Methodology Department, Al Andalous Pharmaceutical Ind., 6thOct.City, Cairo, Egypt \\ ${ }^{2}$ Analytical Chemistry Department, Faculty of Pharmacy, Cairo University, Kasr El-Aini Street, Cairo \\ 11562, Egypt \\ ${ }^{3}$ Pharmaceutical Chemistry Department, Faculty of Pharmacy, University of Alexandria, El-messalah \\ 21521, Alexandria, Egypt
}

*Corresponding author: Hala E Zaazaa, Analytical Chemistry Department, Faculty of Pharmacy, Cairo University, Kasr El-Aini Street, Cairo 11562, Egypt, E-mail: hazaza@hotmail.com, hala. zaazaa@pharma.cu.edu.eg
Received date: 31 Jan 2017; Accepted date: 14 Jul 2017; Published date: 19 Jul 2017.

Citation: Gad M, Zaazaa HE, Amer SM, Korany MA (2017) Quality by Design Approach for Establishment of Stability Indicating Method for Determination of Cefditoren Pivoxil. J Pharm Anal Insights 2(1): doi http://dx.doi.org/10.16966/2471-8122.112

Copyright: (c) $2017 \mathrm{Gad}$ M, et al. This is an openaccess article distributed under the terms of the Creative Commons Attribution License, which permits unrestricted use, distribution, and reproduction in any medium, provided the original author and source are credited.

\begin{abstract}
Quality by design $(\mathrm{QbD})$ approach was successfully used to develop an efficient stability indicating HPLC method for determination of cefditoren pivoxil (CTP) in bulk powder and pharmaceutical formulations. A forced degradation studies were performed under acidic, alkaline, thermal, oxidative and photolytic stress conditions. Chromatographic separation was achieved in less than 10 min; with baseline separation of drug and nine degradation products; using a RP C-18 column, mobile phase: methanol: acetate buffer $0.035 \mathrm{M}$, pH $4.5=55: 45 \mathrm{v} / \mathrm{v}$, flow rate $1.5 \mathrm{~mL} \cdot \mathrm{min}^{-1}$, and UV detection at $225 \mathrm{~nm}$. The method was validated regarding specificity, linearity, precision, accuracy and robustness, CTP response was linear $(r=0.9999)$ in range of $90-670 \mu \mathrm{g} \cdot \mathrm{mL}^{-1}$, the limit of detection (LOD) and limit of quantitation (LOQ) were $5.31 \mu \mathrm{g} \cdot \mathrm{mL}^{-1} \mathrm{and}$ $16.1 \mathrm{\mu g} \cdot \mathrm{mL}^{-1}$, respectively. The intra- and inter-day precisions were $0.11 \%, 0.44 \%$, respectively. The proposed method was successfully applied for the determination of CTP in bulk powder and tablets. Results demonstrated method with a great value for quality control and stability studies applications for CTP.
\end{abstract}

Keywords: Experimental design; AQbD; HPLC; Cefditoren pivoxil; Stability indicating

\section{Introduction}

Cefditoren pivoxil is a third-generation semi-synthetic cephalosporin antibiotic for oral administration. CTP is broad-spectrum antibiotic for treatment of respiratory tract infections [1]. Chemically, Cefditoren pivoxil (Figure 1) is (-)-(6R,7R)-2,2-dimethylpropio-nyloxymethyl7-[(Z)-2-(2aminothiazol-4-yl)-2methoxyiminoacetamido]-3-[(Z)-2-(4-methylthiazol5-yl)ethenyl]-8-oxo-5-thia-1-azabicyclo[4.2.0]oct-2-ene-2carboxylate.

Literature includes various methods for determination of CTP either in plasma [2-4] or in pharmaceutical dosage forms by various spectrophotometric methods [5-7]. Different stability indicating HPLC [810], UPLC [11] and HPTLC [12] methods were also reported. Although, some developed stability indicating methods had studied the hydrolysis of CTP under different stress conditions, but none of them succeeded in separating CTP from all degradation products simultaneously in a single short run; may be due to the complex matrix resulted from hydrolysis of CTP under different conditions. The major benefit from developing method capable to separate the CTP in presence of variety of degradation products resulted from different stress conditions is to challenge the method to conduct acceptable quantitative results under extreme conditions. Traditional approach HPLC method development by trial and error, or by changing one factor at time (OFAT) while holding the rest constant, requires a very large number of experiments to identify the optimal conditions, although, they does not account for interaction between factors.

Quality by design (QbD) is a systematic approach for process development that begins with predefined objectives and emphasizes product, process understanding and process control, based on sound science and quality risk management [13]. Quality by design principles have been applied to the development of analytical methods, and are termed "Analytical QbD" (AQbD) [14-19]. AQbD cycle has different stages, namely definition of analytical target profile, critical quality attribute, conducting risk assessment, method optimization and development using design of experiment (DOE), establishment of method design space, definition of a control strategy. The outcome of $\mathrm{AQbD}$ is a well understood, fit for purpose, and robust method that consistently delivers the intended performance, in addition to straight forward method transfer and method troubleshooting. Application of AQbD approach in development of analytical methods helps to build the quality in the

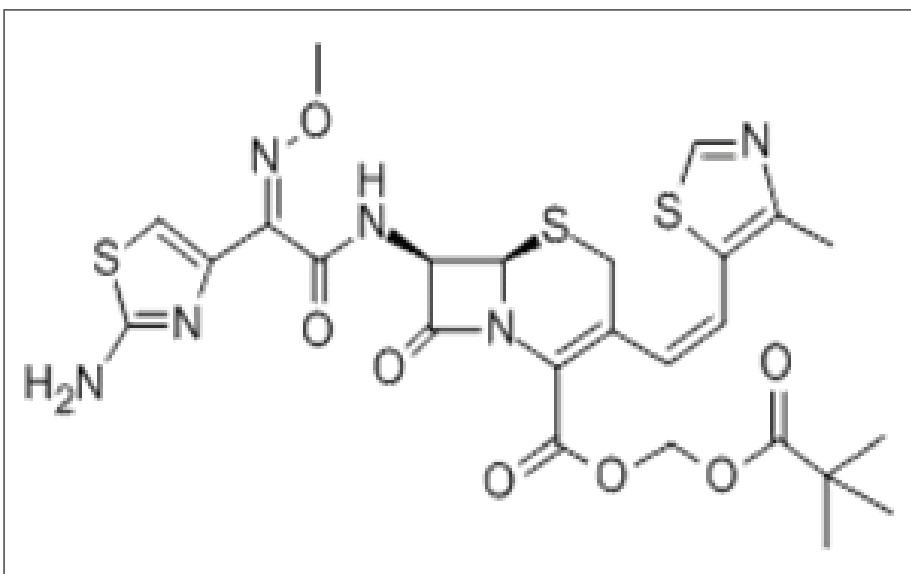

Figure 1: Chemical structure of cefditoren pivoxil (CTP) 
method not mere tests it in the developed method without any previous planning. The broad knowledge during development help establishing a design space [20] that provides suitable method performance in addition to establishment of valuable method controls like system suitability test that can help identify failure modes of method performance and prevent the generation of erroneous results as noted by Gavin and Olsen [21].

The present article aim to develop an efficient stability indicating HPLC method for determination of CTP in the presence of its nine degradation products resulted from acid, alkaline, thermal, oxidative and photolytic stress conditions in a single short run time, which could be applied for CTP applications in routine work of quality control and stability assessment.

\section{Materials and Methods}

\section{Instruments}

An Agilent 1200 HPLC system (Agilent technologies, USA) equipped with quaternary pump (Agilent LC 1200, model G1311A); ultraviolet variable wavelength detector (Agilent LC 1200, model G1314B); autosampler (Agilent LC 1200, model G1329A); Eclipse plus ${ }^{\circledR}$ RP C18 column $100 \times 4.6 \mathrm{~mm}, 3.5 \mu \mathrm{m}$ particle size (Agilent, USA); filtered and degassed $(0.45 \mu \mathrm{m}$ nylon Millipore membrane filter); and UV detection at $225 \mathrm{~nm}$. Samples were filtered through a $0.45 \mu \mathrm{m}$ nylon membrane filter; Analytical balance: model XA205DU (Mettler Toledo, Switzerland); Ultrasonic water bath: model FB15054 (Fisher Scientific, USA); Chemstation ${ }^{\circledR}$ software package for LC systems: Rev B.03.01. Mathematical and statistical manipulations involved in $\mathrm{QbD}$ approach were performed using Design expert ${ }^{\circledR}$ software package Version 7.0.0 (Stat-Ease Inc).

\section{Materials}

Chemicals and reagents: All reagents used were of analytical grade, solvents were of HPLC gradient grade: Methanol (Labscan analytical sciences, New Jersey, U.S.A); sodium chloride; sodium acetate; hydrochloric acid; and sodium hydroxide (E. Merck, Darmstadt, Germany); purified water.

Pure Standard: Cefditoren pivoxil working standard (99.69\%) was supplied by Orchid Pharmaceuticals Co. (India).

Pharmaceutical formulation: A pharmaceutical formulation consisted of croscarmellose, mannitol, magnesium stearate, sodium casienate, sodium tripolyphosphate, in addition to cefditorin pivoxil.

\section{Experimental}

\section{Chromatographic conditions}

Chromatographic separation was conducted, using Eclipse plus ${ }^{\oplus}$ RP C-18 $(100 \mathrm{~mm} \mathrm{l} \times 4.6 \mathrm{~mm}$ i.d, $3.5 \mu \mathrm{m})$ column using acetate buffer $0.035 \mathrm{M}, \mathrm{pH} 4.5 /$ methanol $(45: 55 \mathrm{v} / \mathrm{v})$ as a mobile phase. Where, mobile phase and samples were filtered through $0.45 \mu \mathrm{m}$ Millipore ${ }^{\triangleright}$ membrane filter (Billerica, MA) then degassed for $5 \mathrm{~min}$. Detection wavelength was $225 \mathrm{~nm}$. The system was operated at $40^{\circ} \mathrm{C}$, flow rate at $1.5 \mathrm{~mL} \cdot \mathrm{min}^{-1}$.

\section{Standard solution}

Stock solution of CTP: $4.4 \mathrm{mg} \cdot \mathrm{mL}^{-1}$ in solvent mixture (hydrochloric acid/potassium chloride buffer solution ( $\mathrm{pH} 1.2$ )/Methanol, 1:1 v/v), working solution of CTP: $0.44 \mathrm{mg} \cdot \mathrm{mL}^{-1}$ in solvent mixture.

\section{Assay of pharmaceutical formulation}

Ten tablets are to be grinded into fine powder, an amount of powder equivalent to $44 \mathrm{mg}$ CTP is to be transferred into $100.0 \mathrm{~mL}$ volumetric flask, dissolve in solvent mixture then chromatographed.

\section{Degradation solution}

Ten milliliters from stock standard solution $4.4 \mathrm{mg} \cdot \mathrm{mL}^{-1}$ in methanol of CTP was diluted to $50 \mathrm{~mL}$ using $0.001 \mathrm{M}$ sodium hydroxide solution/ methanol, (alkaline stress conditions), $0.1 \mathrm{M}$ hydrochloric acid/methanol (acid stress conditions), 1\% Hydrogen peroxide/methanol, purified water/ methanol (thermal decomposition) then refluxed for $30 \mathrm{~min}$ at $60^{\circ} \mathrm{C}$. In photolytic hydrolysis; $10.0 \mathrm{~mL}$ from stock standard solution was diluted to $50 \mathrm{~mL}$ using purified water then subjected for direct sun light for 6 hours. Five milliliters aliquot from those solutions were transferred into 100.0 $\mathrm{mL}$ volumetric flask then completed with solvent mixture.

\section{Solutions for assessment of linearity of CTP}

Stock standard solution $\left(4.4 \mathrm{mg} \cdot \mathrm{mL}^{-1}\right)$ of CTP was further diluted with the solvent mixture to obtain seven solutions in the ranges of (90-670 $\mu \mathrm{g}$ $\mathrm{mL}^{-1}$ ). Column was equilibrated with mobile phase before injection, 10.0 $\mu \mathrm{L}$ injections on duplicate base were chromatographed for each solution. The integrated peak areas were plotted against the corresponding concentrations to obtain the calibration graph and regression equation for CTP.

\section{Solutions for assessment of recovery of CTP}

Standard solutions at level of 50\%, 100\%, 150\% of nominal standard concentration spiked with placebo was chromatographed using the previously mentioned chromatographic conditions.

\section{Results and Discussion}

CTP as a cephalosporin is vulnerable to degradation under different conditions producing nine different degradation products. Resolving such a complex mixture by applying traditional HPLC method development is not an easy task, therefore, application of quality by design approach was commenced. CTP forced degradation solutions were prepared under mild conditions targeting generation of $1-30 \%$ degradation of CTP as recommended by Kumar $\mathrm{K}$ et al. [22]. CTP under alkali and oxidative degradation conditions yield $27 \%, 28 \%$ degradation, respectively while under photolytic degradation was $11 \%$. In contrast to Gawande et al. [23] acid degradation was minor about $2.0 \%$, while thermal degradation was $2.5 \%$ degradation, respectively. The previously mentioned degradation solutions were mixed together, in order to prepare a challenging degradation solution containing diverse degradation products that may be generated through the product shelf life. Regarding solution stability a solvent mixture consists of $\mathrm{HCl} / \mathrm{NaCl}$ buffer solution $\mathrm{pH}$ 1.2: methanol, $1: 1 \mathrm{v} / \mathrm{v}$ was found to provide superior stability for CTP in solution where $0.32 \%$ loss in 10 hours occurred at ambient temperature. On the other hand using water: methanol as solvent provided low stability in solution where $2 \%$ loss in 5 hours was observed.

Systematically, first of all an analytical target profile was stated "development and validation of stability indicating HPLC method for quantitative determination of CTP in presence of acid, alkali, oxidative, thermal and photolytic degradation products". Next, enlisting method parameters, critical quality attributes (CQAs) -properties that should be within an appropriate limit, range, or distribution to ensure the desired method quality [20]. Failure mode and effect analysis (FMEA) as a risk assessment tool was used to evaluate method parameters risk on the CQAs. FMEA revealed high risk rank for methanol percentage in mobile phase $(\mathrm{MeOH} \%)$ and elution temperature $(\mathrm{T})$, relatively lower risk rank for buffer $\mathrm{pH}$ on CQAs; While factors like detection wavelength and column type show minor risk rank. The factors with minor risk rank (column type, organic modifier type, flow rate, wavelength) was assigned values based on preliminary trials; buffer $\mathrm{pH}$ was studied in a univariate mode; $\mathrm{MeOH} \%$ and $\mathrm{T}$ as the major risk factors were subjected to extensive study using multivariate design of experiment (DOE) to model them with CQAs. 
System suitability solution was scanned at between $200-400 \mathrm{~nm}$; where $\lambda=225 \mathrm{~nm}$ was the best in terms of sensitivity and precision. However, methanol as organic modifier increases the run time, methanol / RP-C18 column was superior to acetonitrile/RP-C18, acetonitrile/RP-C8 columns or even methanol/RP-C8 in terms of selectivity and number of resolved peaks. As chromatographic run time is critical issue for release testing in quality control, a shorter RP-C18 column with smaller particle size (Eclipse plus ${ }^{\oplus} \mathrm{C} 18100 \times 4.6 \mathrm{~mm} 3.5 \mu \mathrm{m}$ ), flow rate of $1.5 \mathrm{~mL} \cdot \mathrm{min}^{-1}$ was used was used and superior results were obtained.

Two factors central composite design (CCD) with eighteen experiments was used to investigate the response surfaces resulted from interaction between $\mathrm{MeOH} \%$ and $\mathrm{T}$ on each CQA (asymmetry, theoretical plate, resolutions, retention time of last eluted peak as indication on run time). CCD provide a number of desirable features; they are effective designs to estimate curvature of response, provide orthogonal estimates of the polynomial coefficients, and allow for proceeding with the experiment in a stepwise fashion rather than performing the entire design at once. Regarding different constructed models, the intersection area of different models defines the design space (DS)-combinations of temperature and mobile phase methanol percentage that satisfies predefined values of all CQAs Table 1.

Design expert 7.0.0 software package was used to manipulate mathematical, statistical calculations and predictions in addition to defining the design space (DS) that satisfies all CQAs predefined limits. Analysis of experimental data resulted in construction of response surfaces for asymmetry, theoretical plate number, resolution and retention time of last eluted peak as function of $\mathrm{MeOH} \%$ and T. (Figure 2) demonstrates the resulted response surfaces while Table 2 demonstrates a statistical summary of the constructed models. It worth to mention that theoretical plate number $(\mathrm{N})$ was transformed into reciprocal $[1 / \mathrm{N}]$ before modeling in order to achieve better model fitting with minimum model's order and more randomly distributed residuals. Moreover, to verify acceptable prediction of the models they were challenged by conducting HPLC system at intermediate points within the design space followed by comparing the practically obtained CQA with the predicted ones, where most of the practically obtained values were within $90-106 \%$ of the predicted values. Finally, CQAs were prioritized according to the desirability of

Table 1: Critical quality attributes (CQAs) and relevant predefined limits for CTP

\begin{tabular}{|l|c|}
\multicolumn{1}{|c|}{ CQA } & Predefined limit(s) \\
\hline Peak asymmetry $^{\mathrm{a}}$ & 0.9 to 1.0 \\
\hline Theoretical plate number $^{\mathrm{a}}$ & NLT 4000 \\
\hline Pre-resolution $^{\mathrm{b}}$ & NLT 4 \\
\hline Post-resolution $^{\mathrm{c}}$ & NLT 4 \\
\hline${\text { Retention time of LEP }[\mathrm{min}]^{\mathrm{d}}}^{\mathrm{d}}$ & NMT 10 (minimize) \\
\hline
\end{tabular}

avalue with respect to CTP.

${ }^{\mathrm{b}} \mathrm{CTP}$ peak relative to the previous peak.

${ }^{\mathrm{C}} \mathrm{CTP}$ peak relative to the next peak.

${ }^{d} \mathrm{LEP}=$ last eluted peak.

Table 2: Models statistical summary

\begin{tabular}{|l|c|c|c|}
\multicolumn{1}{|c|}{ CQA } & Model type & R-Squared & $\begin{array}{c}\text { Adjusted } \\
\text { R-Squared }\end{array}$ \\
\hline Asymmetry & Linear & 0.931 & 0.893 \\
\hline 1/Plate No. & $2 \mathrm{FI}^{\mathrm{a}}$ & 0.941 & 0.927 \\
\hline Pre-Res & Quadratic & 0.963 & 0.951 \\
\hline Post-Res & Quadratic & 0.993 & 0.991 \\
\hline Last peak retention time & Quadratic & 0.985 & 0.978 \\
\hline
\end{tabular}

aTwo factor interaction. maximizing the theoretical plate number of CTP and minimizing the run time, resulting in definition of an area between 54-56.5 methanol\% and $34-40^{\circ} \mathrm{C}$ as control space - the combinations of temperature and mobile phase methanol percentage that satisfy chromatographic process with maximum number of plates at minimum run time. Furthermore, normal operation parameters (NOP) " 55 methanol\% and $40^{\circ} \mathrm{C}$ " were identified as the point of maximum desirability within the control space. Figure $3 \mathrm{a}$, overlay plot of response surfaces shows the DS in white, which includes control space and NOP while Figures $3 \mathrm{~b}$ demonstrates a contour plot of desirability function as applied to DS where the red area represents the maximum desirability area of control space down to blue area which is the area of zero desirability.

In a univariate mode, the effect of different buffers in mobile phase was studied. Phosphate buffer $\mathrm{pH} 2.5,3.5,6.5$; acetate buffer $\mathrm{pH}$ 4.5, 5.5 were used. Figures (4a-d) show the effect of buffer $\mathrm{pH}$ on CTP asymmetry $\left(\mathrm{A}_{\mathrm{s}}\right)$, theoretical plate number $(\mathrm{N})$, resolution (pre- $\mathrm{R}_{\mathrm{S}}$ \& post- $\mathrm{R}_{\mathrm{S}}$ ) and retention time of last eluted peak was demonstrated. Inspection of figures concluded selection of sodium acetate/acetic acid buffer $\mathrm{pH} 4.5$ as it provides superior CQAs response results. In addition to high buffer capacity at $\mathrm{pH}$ 4.5 which favor neglecting sample solvent $\mathrm{pH}$ effect when conducting biowaiver studies providing wide application scope for the method. Finally, Table 3 summarizes normal operating parameters while Figure 5 shows typical chromatogram at NOP illustrates the resolution of CTP from its nine degradation products in less than ten minutes.

\section{Method Validation}

Specificity: Standard solution spiked with forced degradation products was chromatographed; CTP peak was complete resolved from those of degradation products. In addition, absence of interference between CTP and excipients as indicated by placebo solution chromatogram. The chromatographic selectivity factor and chromatographic resolution between CTP and degradation products illustrated in Table 4 indicate adequate method specificity.

Linearity: Under normal operating parameters, a linear relationship was obtained by plotting the drug concentrations against integrated peak areas for CTP. The corresponding concentration range, regression equation and other statistical parameters were listed in Table 5.

Accuracy: The accuracy of method was indicated by analysis of placebo-spiked CTP standard at three CTP concentration levels: 50, 100 and $150 \%$ where nine preparations had been injected on duplicate basis, the mean recovery for all concentration levels, in addition to the grand mean and standard deviation had been calculated and summarized in Table 5. The results of the proposed method were statistically compared to that of M. Mathrusri Annapurna et al. stability indicating method [24] as reference method using Hypersil BDS ${ }^{\circledR} \mathrm{C} 18(4.6 \times 250 \mathrm{~mm}), 5 \mu \mathrm{m}$ particle size column, water: Acetonitrile $(50: 50 \mathrm{v} / \mathrm{v})$ as a mobile phase, flow rate of $1.2 \mathrm{~mL} \mathrm{~min}^{-1}$ and UV detection at $218 \mathrm{~nm}$. The comparison indicated insignificant difference between both methods Table 6 .

Precision: Precision was evaluated by calculating intra-day precision on duplicate bases, calculating the recovery percentage of six different standard solutions at concentration level equivalent to $100 \%$ of designed standard concentration. A relative standard deviation (RSD) of $0.11 \%$ indicates acceptable intra-day precision of the proposed method. Interday precision was conducted by analysis of other six different standard solutions on duplicate bases in another day, RSD of $0.44 \%$ also indicates satisfactory inter-day precision, results are summarized in Table 5.

Robustness: Method robustness was investigated considering the most critical parameters affecting chromatographic process namely; elution temperature and mobile phase methanol percent. The mobile 
phase methanol content percentage was varied (53\%, 55\% and 57\%). CTP percentage recoveries relative to optimum methanol percent (55\%) were evaluated to be $101.1,101.3 \& 101.4 \%$, respectively. For temperature robustness evaluation a standard solution was chromatographed at different column temperatures $\left(38,40\right.$ and $\left.42^{\circ} \mathrm{C}\right)$, regarding CTP response, the recovery percentage relative to optimum column temperature $\left(40^{\circ} \mathrm{C}\right)$ were evaluated to be $100.3,100.5 \& 101.1 \%$ respectively.
Limit of detection (LOD) and Limit of quantitation (LOQ): Seven standard preparations $\left(90 \mu \mathrm{g} \cdot \mathrm{mL}^{-1}-670 \mu \mathrm{g} \cdot \mathrm{mL}^{-1}\right)$ were analyzed, and the corresponding peak areas versus concentration were used to estimate the regression equation, from which LOD and LOQ were calculated (3.3 and 10.0 times the standard deviation of regression line divided by slope of regression line, respectively), to be $5.31 \mu \mathrm{g} \cdot \mathrm{mL}^{-1}$ and $16.10 \mu \mathrm{g} \cdot \mathrm{mL}^{-1}$, respectively.
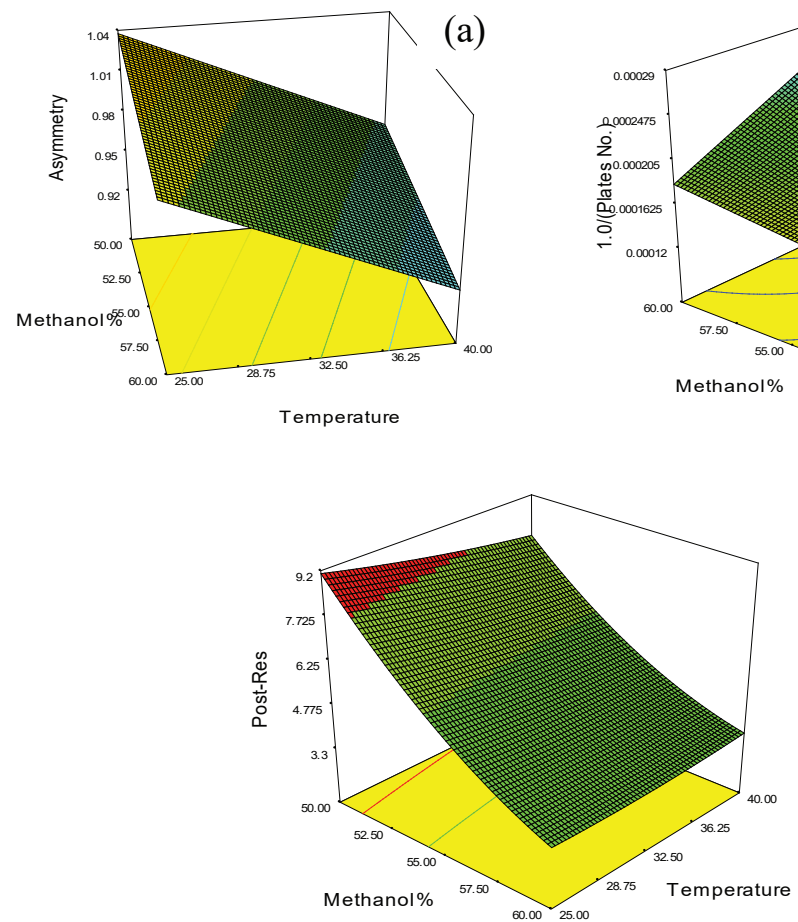

(b)

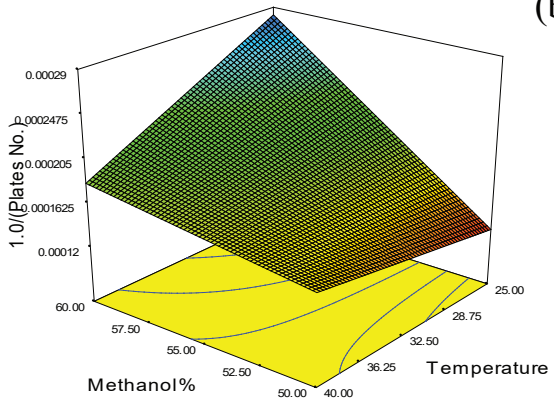

(c)

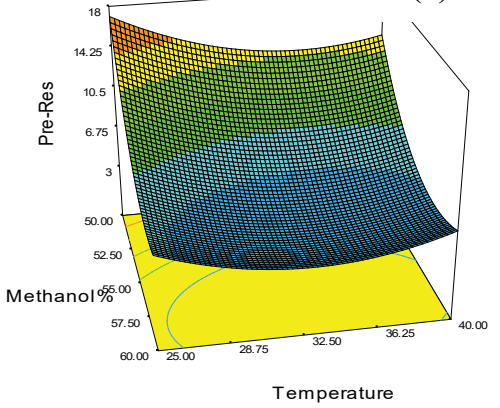

(d)

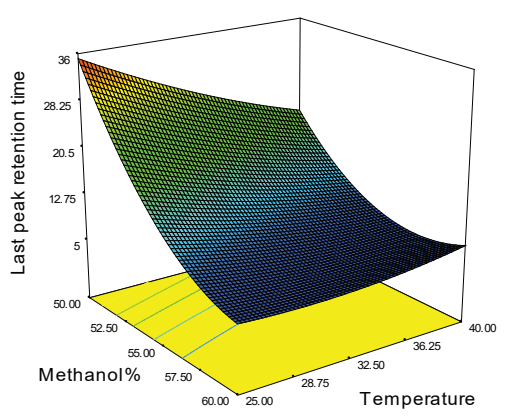

(e)

Figure 2: Response surface "(a) CTP asymmetry; (b) reciprocal CTP theoretical plate number (N); (c) CTP pre- resolution, (d) CTP post-resolution; (e) last peak retention time" as function of mobile phase methanol\% and elution temperature $\left({ }^{\circ} \mathrm{C}\right)$

a)

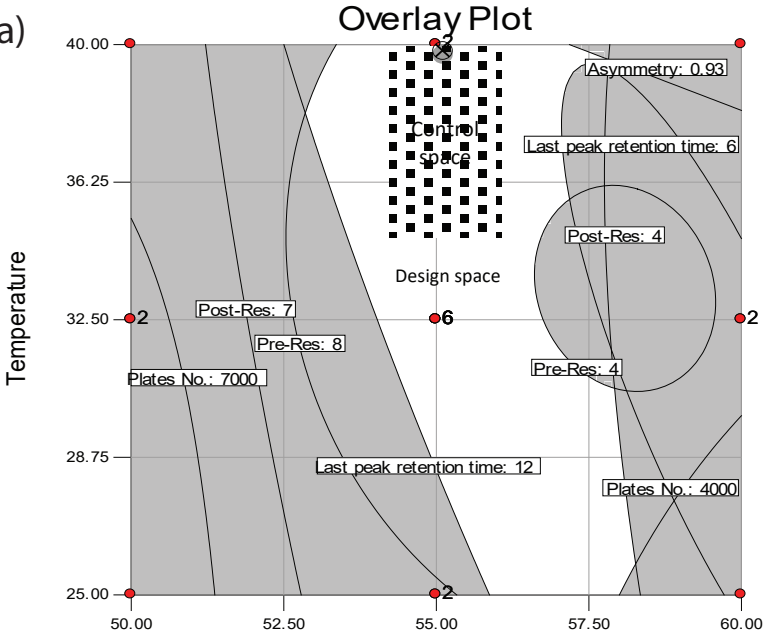

Methanol\% b)

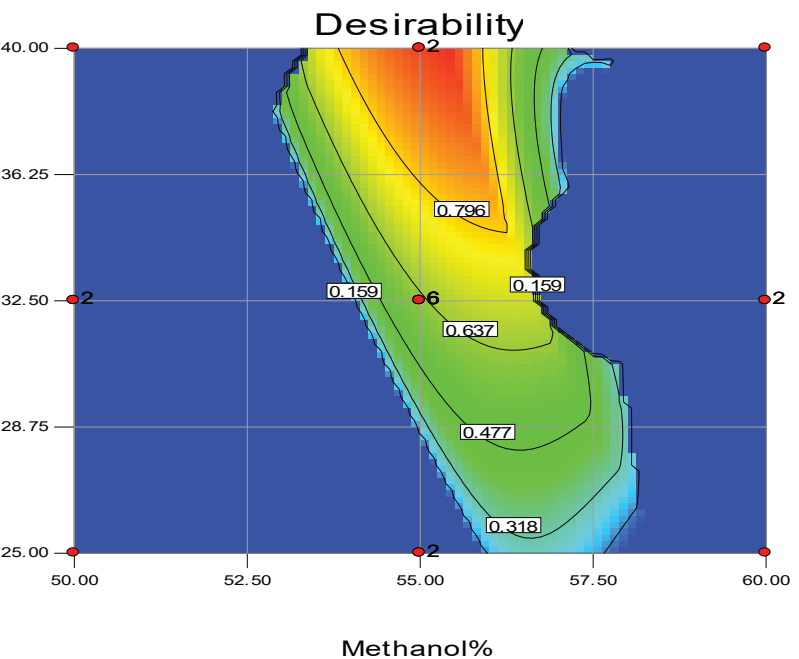

Figure 3a: Overlay plot of all response surfaces showing the failure space "gray area", design space "white area", control space "dotted area" and cross point normal operation parameters

Figure 3b: Two dimension Desirability plot of design space

Citation: Gad M, Zaazaa HE, Amer SM, Korany MA (2017) Quality by Design Approach for Establishment of Stability Indicating Method for Determination of Cefditoren Pivoxil. J Pharm Anal Insights 2(1): doi http://dx.doi.org/10.16966/2471-8122.112 
a)

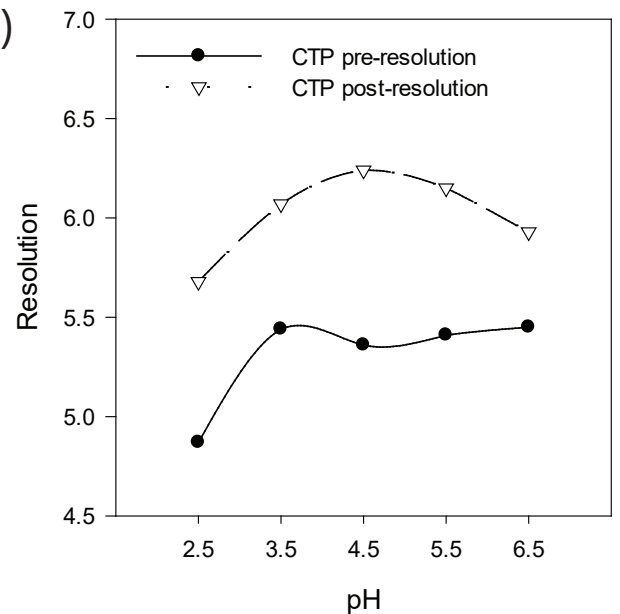

C)

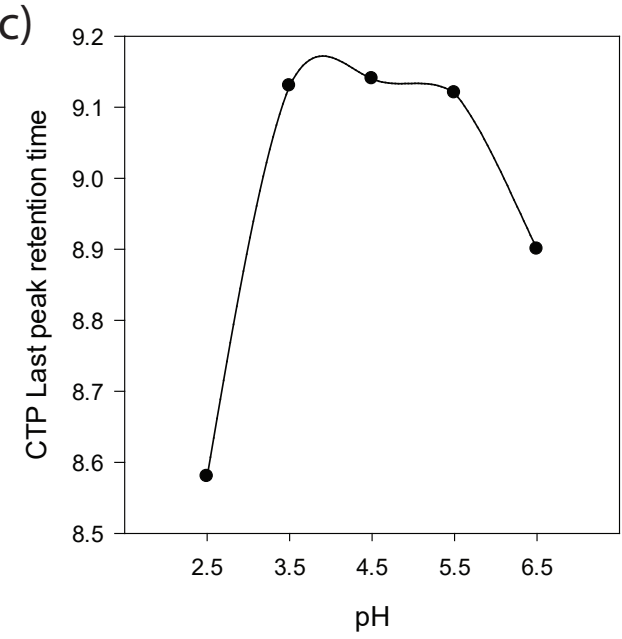

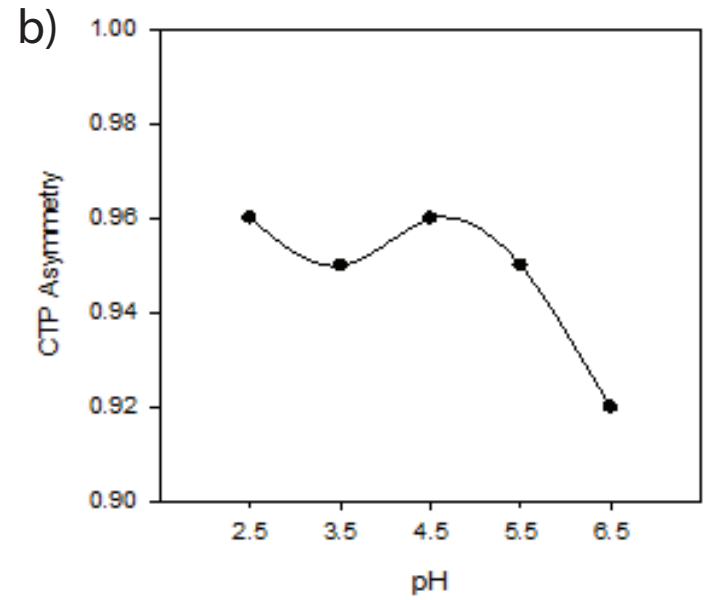

d)

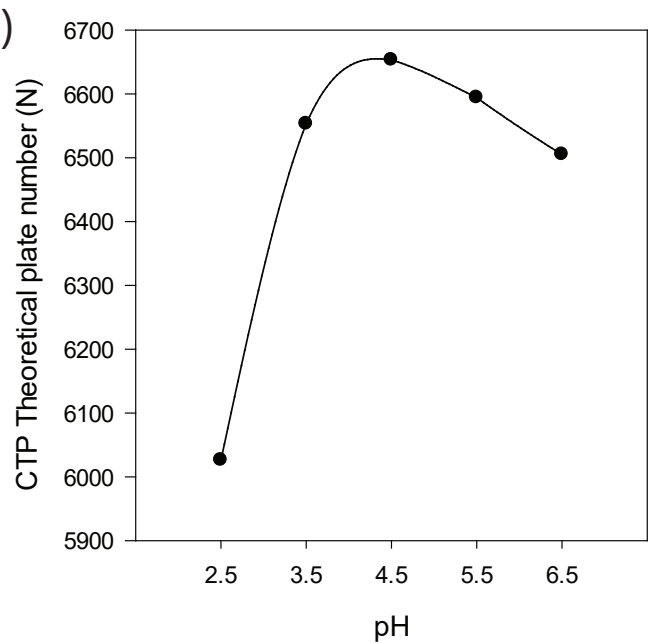

Figure 4a: Effect of mobile phase buffer $\mathrm{pH}$ on Resolution between CTP and previous or next eluted peaks

Figure 4b: Effect of mobile phase buffer $\mathrm{pH}$ on CTP peak asymmetry

Figure 4c: Effect of mobile phase buffer $\mathrm{pH}$ on Retention time of last eluted peak

Figure 4d: Effect of mobile phase buffer $\mathrm{pH}$ on CTP peak theoretical plate number

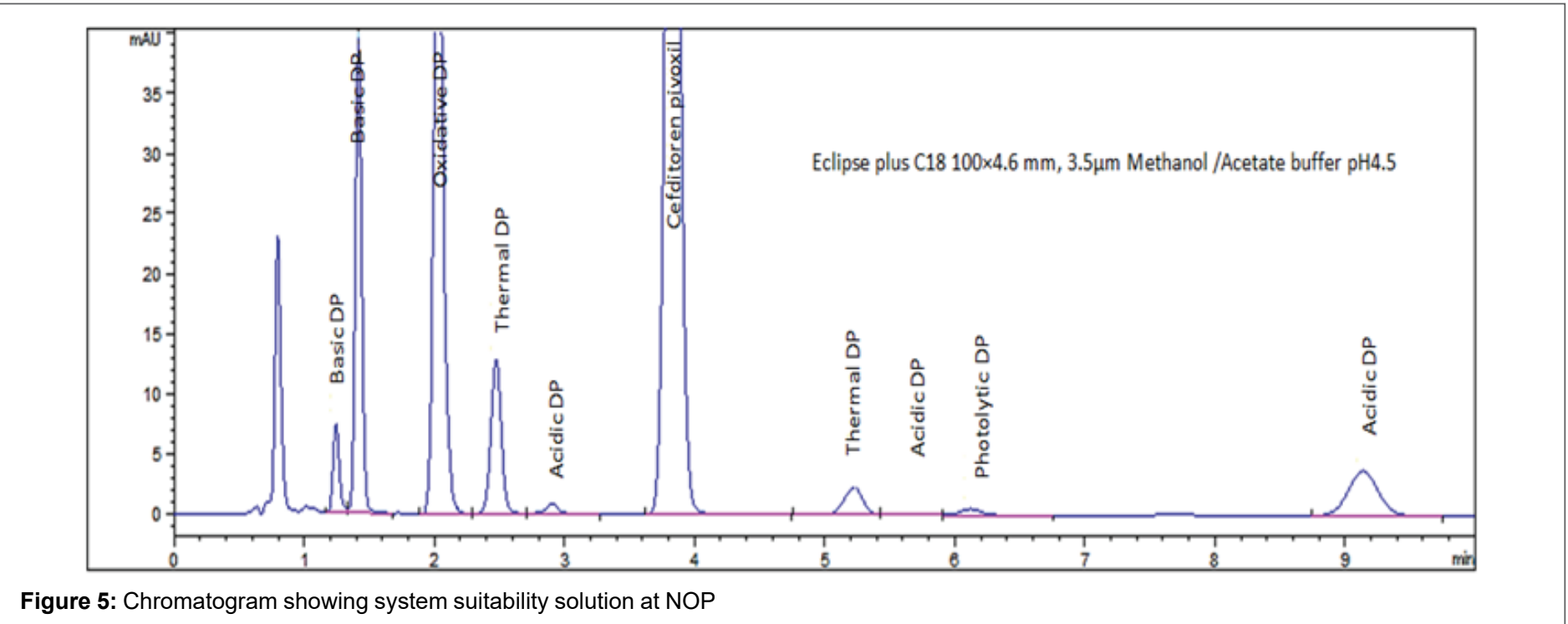

Citation: Gad M, Zaazaa HE, Amer SM, Korany MA (2017) Quality by Design Approach for Establishment of Stability Indicating Method for Determination of Cefditoren Pivoxil. J Pharm Anal Insights 2(1): doi http://dx.doi.org/10.16966/2471-8122.112 
Table 3: Normal operation parameters (NOP)

\begin{tabular}{|l|c|}
\multicolumn{1}{|c|}{ Parameters } & Value \\
\hline Mobile phase & Acetate buffer $0.035 \mathrm{M}, \mathrm{pH} 4.5:$ Methanol = 45:55 \\
\hline Flow rate $[\mathrm{mL} / \mathrm{min}]$ & 1.5 \\
\hline Temperature $\left[{ }^{\circ} \mathrm{C}\right]$ & 40 \\
\hline injection volume $[\mu \mathrm{L}]$ & 10 \\
\hline Wavelength $[\mathrm{nm}]$ & 225 \\
\hline
\end{tabular}

Table 4: Results of system suitability parameters for the proposed HPLC method

\begin{tabular}{|c|c|c|c|c|c|c|c|c|c|c|c|}
\hline Parameters & í & $\frac{\mathbf{N}}{\mathbf{a}}$ & a & $\begin{array}{l}\text { वे } \\
\text { a }\end{array}$ & مُ & $\frac{a}{b}$ & $\begin{array}{l}0 \\
\vdots \\
0\end{array}$ & $\hat{a}$ & $\begin{array}{l}\infty \\
0 \\
0\end{array}$ & $\begin{array}{l}0 \\
\text { an }\end{array}$ & Reference value \\
\hline Resolution $(R)$ & 1.95 & 5.3 & 2.7 & 3.16 & 5.56 & 6.21 & 1.1 & 2.25 & 8.44 & & $R>1.5$ \\
\hline CTP Asymmetry factor (T) & 0.95 & & & & & & & & & & $0.9-1.1$ \\
\hline CTP Capacity factor $(K)$ & 2.82 & & & & & & & & & & $1-10$ \\
\hline CTP Column efficiency $(N)$ & 6700 & & & & & & & & & & $>4000$ \\
\hline
\end{tabular}

*degradation products (DP\#) numbered according to order of elution

Table 5: Analytical parameters and validation results for determination of CTP by the proposed method

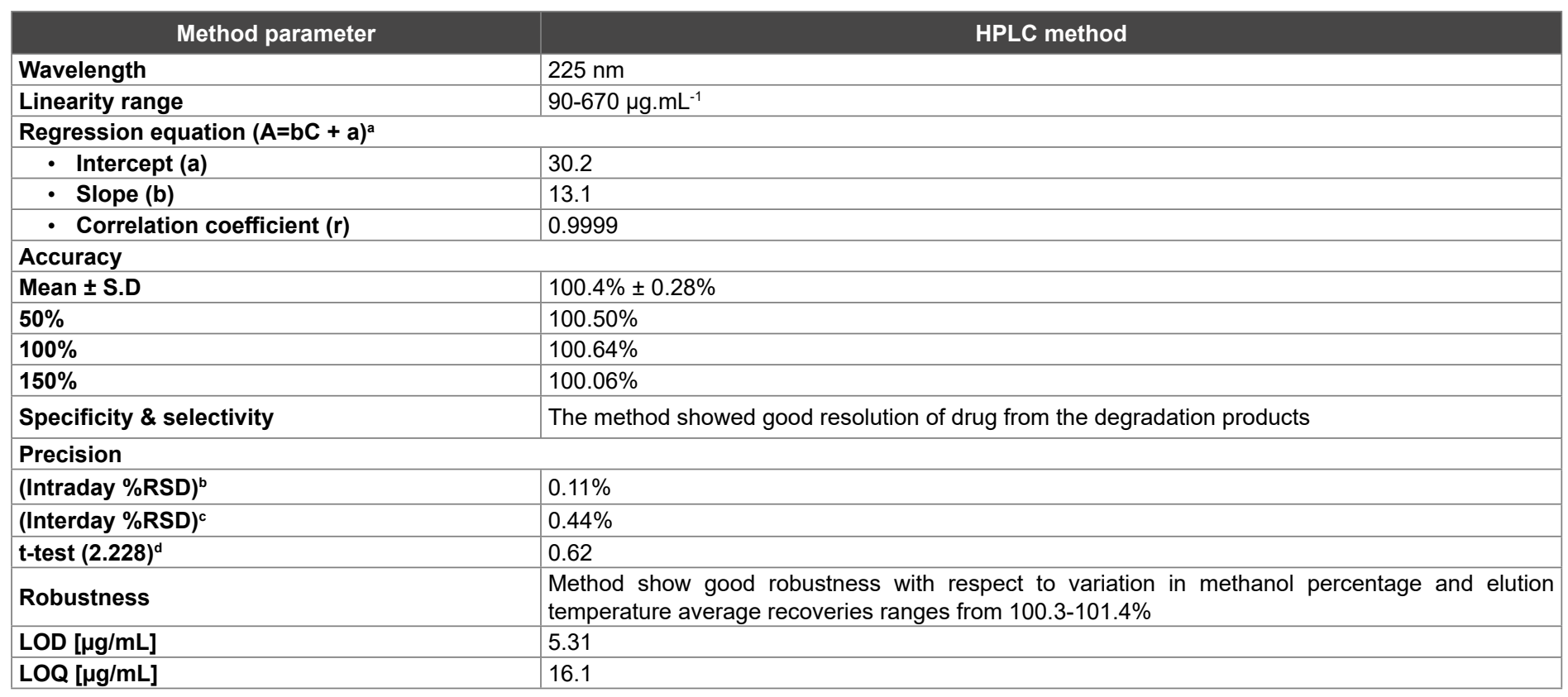

${ }^{\mathrm{a}} \mathrm{A}$ is the peak area and $\mathrm{C}$ is the concentration.

bIntraday precision (6different determinations at $100 \%$ concentrations of $/ 2$ replicate each $(n=6)$ )

Interday precision ( 6 different determinations at $100 \%$ concentrations of $/ 2$ replicate each $(n=6)$ ).

dt-tabulated for degree of freedom $=10$, two sided test at $\alpha=0.05$.

Table 6: Statistical comparison between proposed and reported method for the determination of CTP in pure powder form

\begin{tabular}{|c|c|c|}
\hline \multirow{2}{*}{ Item } & \multicolumn{2}{|c|}{ Cefditoren pivoxil } \\
\hline & Proposed method & Reported method \\
\hline Mean \pm St.dev & $99.89 \pm 0.69$ & $99.92 \pm 0.60$ \\
\hline $\mathrm{n}$ & 7 & 7 \\
\hline F- value $(4.28)^{b}$ & \multicolumn{2}{|c|}{0.75} \\
\hline Student's t-test $(2.45)^{b}$ & \multicolumn{2}{|c|}{0.09} \\
\hline
\end{tabular}

aReported method: HPLC method, using Hypersil TM BDS C18 $(4.6 \times 250 \mathrm{~mm}) 5 \mu \mathrm{m}$ column, water- Acetonitrile $(50: 50 \mathrm{v} / \mathrm{v})$ as a mobile phase, flow rate of $1.2 \mathrm{ml} \mathrm{min}{ }^{-1}$ and UV detection at $218 \mathrm{~nm}$ [24].

${ }^{\mathrm{b}}$ The figures in parenthesis are the corresponding tabulated values at $\alpha=0.05$

Citation: Gad M, Zaazaa HE, Amer SM, Korany MA (2017) Quality by Design Approach for Establishment of Stability Indicating Method for Determination of Cefditoren Pivoxil. J Pharm Anal Insights 2(1): doi http://dx.doi.org/10.16966/2471-8122.112 


\section{Conclusion}

QbD development approach introduced a mechanical understanding of method parameters influencing chromatographic separation, in addition to, maximum robustness and high confidence in method ability to deliver intended performance. Design space created during method development, enabled flexibility of method transfer and application. Moreover, provide guidance for troubleshooting method performance. The proposed method was successful in establishment of good resolution among cefditoren pivoxil and nine degradation products well above baseline separation, with a run time of less than $10 \mathrm{~min}$. Validation results demonstrated highly specific, accurate and precise method performance.

\section{References}

1. Balbisi EA (2002) Cefditoren: a new amino thiazolyl cephalosporin. Pharmacotherapy10: 1278-1293.

2. Vishal DM, Anurath SP, Ashwini M (2011) Determination of Cefditoren Pivoxil In Human Plasma by High Performance Thin Layer Chromatographic Method. Int J Res Ayur Pharm 25: 1582-1584.

3. Rieck W, Platt D (2000) Determination of Cefditoren (ME 1206) In the Plasma of Elderly Patients with Multiple Diseases Using HighPerformance Liquid Chromatography. Clin Lab 46: 477-482.

4. Liu Q, Yao JH, Su CY (2006) Bioequivalence of Cefditorenin human and pharmacokinetics of absorption in rat. Asian $\mathrm{J}$ Pharmacodyn Pharmacokinet 4: 6214-6218.

5. Niraimathi V, Aruna A, Suresh AJ, Prema V (2010) Spectrophotometric Estimation of Cefditoren Pivoxil in Pharmaceutical Oral Solid Dosage Form. Int J Chem Sci 8: 724-728.

6. Rao N S, Saraswathi K (2011) Validated Spectrophotometric methods for the Determination of Cefditoren Pivoxil in Drug Formulations. Int J Chem Tech Research 3: 1025-1027.

7. RajuSA, KaradiAB, Manjunath S (2009) Visible Spectrophotometric Determination of Cefditoren Pivoxil in Pharmaceutical Formulations. J Ind Council Chem 26: 2654-2657.

8. Mathrusri MA, Goutam SVS, Anusha S, Srinivas L (2012) Development And Validation of The Stability-Indicating LC-UV Method For The Determination of Cefditoren Pivoxil. J Pharm Anal 2: 466-469.

9. Rao NS, Saraswathi K (2011) RP-HPLC Methods For The Determination Of Cephalosporins (Cefditoren Pivoxil And Cefdinir) in Pharmaceutical Dosage Forms. J Pharm Sci Res 3: 1002-1004.

10. Dewani P , Kochar NI, Abooj HC (2010) Determination of Cefditoren Pivoxil in Bulk by RP-HPLC in Presence of Its Degradation Products. J Pharm Res 3: 2588-2591.
11. Garg R , Singh N, Srinivas KS, Deb B, Ahmed A (2011) UPLC Method Development and Validation For Cefditoren Pivoxil in Active Pharmaceutical Ingredient. J App Pharm Sci 1: 149-153.

12. Narayana PS , Reddy AS, Sekar R (2012) Development and validation of a HPTLC Method for Stability Indicating Assay of Cefditoren Pivoxil, a Third Generation Cephalosporin Antibiotic in both Bulk Drugs and Pharmaceutical Dosage Forms. J Pharm Res 5: 1628-1632.

13. Lionberger RA, Lee SL, Lee LM, Raw A, Yu LX (2008) Quality by Design: Concepts for ANDAs. The AAPS J 10: 268-276.

14. Borman $P$, Nethercote $P$, Chatfield M, ThompsonD, Truman K (2007) The Application of Quality by Design to Analytical Methods. Pharm Tech 31: 142-152.

15. Schweitzer M, Pohl M, Brown MH, Nethercote P, Borman $P$, et al. (2010) Implications and Opportunities of Applying QbD Principles to Analytical Measurements. Pharm Tech 34: 52-59.

16. Vogt FG, Kord AS (2011) Development of Quality-By-Design Analytical Methods. J Pharm Sci 100: 797-812.

17. Krull I, Swartz M, Lukulay PH, Turpin J, Verseput R (2008) A Qualityby-Design Methodology for Rapid LC Method Development, Part I. LCGC North America 26: 1190-1197.

18. Krull I , Swartz M, Turpin J, Lukulay PH, Verseput R (2009) A Qualityby-Design Methodology for Rapid LC Method Development Part II. LCGC North America 27: 48-61.

19. Ling S, McBrien M (2011) A Quality by Design Approach to Chromatographic Method Development. Int J Anal Chem 7: 16-20.

20. Karmarkar S, Garber R, Genchanok Y, George S, Yang X, et al. (2011) Quality by Design (QbD) Based Development of a Stability Indicating HPLC Method for Drug and Impurities. J Chromatogr Sci 49: 439-446.

21. Olsen BA, Gavin PF (2008) A quality by design approach to impurity method development for atomoxetine hydrochloride (LY139603). J Pharm Biomed Anal 46: 431-441.

22. Hotha KK, Kumar Reddy SP, Kishore V, Ravindranath LK (2013) Forced degradation studies: practical approach-overview of regulatory guidance and literature for the drug products and drug substances. Int Res J Pharm 4: 78-85.

23. Gawande VT, Bothara KG, Singh A, Mahajan AA (2015) Identification and characterization of hydrolytic degradation products of cefditoren pivoxil using LC and LC-MS/TOF. Indian J Pharm Sci 77: 75-82.

24. Annapurna M M , Goutam SVS, Anusha S, Srinivas L (2012) Development and validation of the satbility-indicating LC-UV method for the determination of cefditoren pivoxil. J Pharm Anal 2: 466-469. 